\title{
Facilitation of Extinction by an Increase or a Decrease in Trial Duration
}

\author{
Mark Haselgrove and John M. Pearce \\ Cardiff University
}

\begin{abstract}
Five experiments examined the effects of altering the duration of a conditioned stimulus (CS) for extinction. For the first 3 experiments, rats received conditioning with a 10-s CS before different groups received extinction with a CS that was either the same duration or longer than that used for conditioning. For the remaining 2 experiments, conditioning was conducted with a 60-s CS before different groups received extinction with a CS of either the same duration or a shorter duration than that used for conditioning. In all experiments, extinction progressed more readily when the CS duration was different for the 2 stages than when it was constant. The results are discussed in terms of rate expectancy theory and associative learning theory.
\end{abstract}

Typically, studies of extinction in Pavlovian conditioning involve pairing a conditioned stimulus (CS) of a fixed duration with an unconditioned stimulus (US) before the same duration of CS is presented in the absence of the US. Experiments based on this design have identified a number of factors that influence extinction. The nature of the reinforcement schedule during acquisition is important, with partial reinforcement generally resulting in a greater number of trials until extinction is complete than continuous reinforcement (Gibbon, Farrell, Locurto, Duncan, \& Terrace, 1980; Pearce, Redhead, \& Aydin, 1997; Rescorla, 1999b; but see Pavlik \& Carlton, 1965; Pavlik \& Collier, 1977). Extinction can also be affected by the interval between successive presentations of the CS. Responding tends to be weaker when this interval is short than when it is long (Rescorla \& Durlach, 1987; see Mackintosh, 1974, for a review). The purpose of the present article is to examine the influence of another factor that has been said to influence extinction.

During extinction, animals are exposed to an increasing number of trials as well as an increasing duration of nonreinforced exposure to the CS. The question is then raised as to whether it is the progressive increase in the number of nonreinforced trials that is responsible for extinction or the progressive increase in the duration of nonreinforced exposure to the CS. Initial attempts to address this question involved training rats with an avoidance task in which responses during a signal prevented shock that would otherwise be presented on its termination. After such training, subjects received equal durations of nonreinforced exposure to the signal, which was presented in the form of either many shortduration trials or few long-duration trials. During the extinction stage, it was not possible to perform the avoidance response, but subjects were able to make this response during a final test stage in which the effectiveness of the extinction treatments was as-

This research was supported by a grant from the Biotechnology and Biological Sciences Research Council of the United Kingdom. We thank Peter Jones for his assistance with the experiments.

Correspondence concerning this article should be addressed to Mark Haselgrove or John M. Pearce, School of Psychology, Cardiff University, Cardiff CF10 3YG, United Kingdom. E-mail: haselgrovem@ cardiff.ac.uk or pearcejm@cardiff.ac.uk sessed. In some studies, no difference was found between the effects of the different treatments (Schiff, Smith, \& Prochaska, 1972; Sherman, 1970), and in others exposure to many short trials resulted in stronger responding than exposure to few long trials (Berman \& Katzev, 1972). There is one report in which many short extinction trials resulted in weaker responding than a few long trials (Polin, 1959), but these result are particularly difficult to interpret because rats in one extinction condition, but not the other, were allowed to make the avoidance response. The other studies that have been cited were better designed in this respect but, as Shipley (1974) pointed out, the use of an active avoidance task hampers the interpretation of their results by permitting different subjects to receive different numbers of pairings of the signal with shock during acquisition.

To determine whether the number of extinction trials or the duration of exposure to the CS governs extinction, Shipley (1974) used Pavlovian conditioning in which either a 25 -s or a 100 -s CS signaled shock. He found that, provided the same amount of exposure to the CS was given, extinction was just as effective when each extinction trial lasted for either $25 \mathrm{~s}$ or for $100 \mathrm{~s}$. On the basis of these results as well as similar findings using an active avoidance task by Shipley, Mock, and Levis (1971), Shipley proposed that the extinction of fear is a function of the total amount of nonreinforced exposure to the CS.

However, in the study by Shipley (1974), conditioning took place in a different context to that used for the rest of the experiment, and instead of monitoring responding during extinction, the effects of nonreinforcement were assessed in a test session that was conducted at varying intervals after the final extinction trial. This methodology might have minimized differences between the groups that would have been evident if responding had been observed during each extinction trial. To determine whether the proposal of Shipley is correct, therefore, the reported experiments compared the effects of conducting extinction with many short trials or few long trials, and performance was studied continuously throughout extinction. In Experiments 1 and 2, groups of rats were conditioned with a CS of short duration and then received extinction trials in which the duration of the CS was either the same or longer than that during acquisition. The groups received the same number of trials so that some of them received more exposure to the CS than others. If the amount of exposure to the CS, rather than 
the number of extinction trials, is the more important determinant of extinction, then extinction will be more effective for the groups receiving the longer trial duration in extinction. For the final three experiments, different groups of rats again received different trial durations during extinction, but the number of trials given to each group ensured they received the same total duration of exposure to the CS. According to the proposals of Shipley (1974), there should be no difference between the results from the groups when they are compared after receiving identical durations of exposure to the CS.

In addition to providing further information about the factors that affect extinction, the following experiments were designed to evaluate an account of extinction that Gallistel and Gibbon (2000) derived from their rate expectancy theory. They suggested that during extinction, subjects are continually making a decision about when to stop responding. This decision is based on a comparison between the expected duration of exposure to the CS between successive presentations of the US (IRI $\mathrm{CS}_{\text {S }}$ ) and the amount of time in the presence of the CS since the US was last presented $\left(\mathrm{I}_{\mathrm{CS} \text { no R }}\right)$. Responding will cease when the ratio of these durations, $\mathrm{I}_{\mathrm{CS}}$ no $\mathrm{R} /$ $\mathrm{IRI}_{\mathrm{CS}}$, exceeds a predetermined threshold. Support for this proposal comes from the finding that extinction progresses more slowly after conditioning with a partial than a continuous reinforcement schedule (Gibbon et al., 1980). According to rate expectancy theory, given the same trial duration, continuous reinforcement will involve less exposure to the CS between successive presentations of the US than partial reinforcement and thereby require fewer extinction trials before the threshold is exceeded.

As far as the proposed experiments are concerned, it follows from rate expectancy theory that if two groups are conditioned with the same CS duration and then receive extinction with that duration or with one that is different, then the effects of extinction will be equivalent provided both groups receive identical amounts of exposure to the CS. Alternatively, if the groups should receive the same number of trials in extinction, then extinction will progress more rapidly with the group that receives the longer $\mathrm{CS}$, provided that both groups receive the same training during conditioning.

A rather different account of extinction is provided by associative theories of conditioning. The repeated pairing of a CS and US, according to these theories, will result in the growth of a connection between their internal representations, with the strength of this connection influencing the strength of the response elicited by the CS. Extinction is then said to be effective by weakening the influence of the CS-US association. As Gallistel and Gibbon (2000) noted, a problem confronted by some of these theories (e.g., Pearce, 1994; Rescorla \& Wagner, 1972) is that of specifying when nonreinforcement will result in a reduction of the associative strength of a CS. In terms of the Rescorla-Wagner (1972) theory, for example, it is not immediately obvious how a manipulation such as extending the length of the CS for extinction will be effective. To avoid undue repetition, we shall postpone discussion of the way in which associative theories of extinction might be applied to the proposed experiments until their results are known.

\section{Experiment 1}

For the first experiment, three groups of rats initially received appetitive Pavlovian conditioning in which a 10-s CS was paired with food. They then received extinction in which the duration of each trial was $10 \mathrm{~s}$ for the $10-10$ group, $30 \mathrm{~s}$ for the $10-30$ group, and 270 s for the 10-270 group. There were six trials in each of six sessions of extinction. Accordingly, the three groups received the same number of extinction trials but different amounts of nonreinforced exposure to the CS. Two steps were taken to retard the rate of decline of responding during extinction and thereby enhance the likelihood of detecting differences between the groups. First, conditioning was conducted using a partial reinforcement schedule. This manipulation has been found to retard extinction with a similar method of conditioning to that used for the present experiments (e.g., Pearce et al., 1997). Second, on reinforced trials, food was presented either 5 or $10 \mathrm{~s}$ after CS onset. Pilot experiments have shown that this method may also retard extinction.

The proposals of Gallistel and Gibbon (2000) were evaluated by using three different methods to examine the results. For one method, the strength of the conditioned response (CR) was monitored during the first $10 \mathrm{~s}$ of each extinction trial. On the basis of this measure, the performance of the three groups should differ as extinction progresses, because for each group, the first $10 \mathrm{~s}$ of each trial (except the first) will be preceded by different amounts of exposure to the CS since food was delivered. More specifically, responding during the first $10 \mathrm{~s}$ of the $\mathrm{CS}$ should weaken most rapidly in the 10-270 group, to a lesser extent in the 10-30 group, and least of all in the 10-10 group. A second method allowed responding to be compared between the three groups after they had received equivalent amounts of exposure to the CS. Thus a record was taken of magazine activity for each $10 \mathrm{~s}$ of exposure to the CS throughout extinction. On the basis of this measure, the theory of Gallistel and Gibbon (2000) predicted there will be no difference between the groups across successive intervals because they will have received identical durations of exposure to the nonreinforced CS.

According to Gallistel and Gibbon (2000), extinction occurs when subjects decide to stop responding, and the third method for examining the results was used to reveal when this decision had been made. To overcome the problem of identifying when a subject has decided to give up responding, we used the extinction criterion adopted by Gallistel and Gibbon (p. 306) of a decline to $50 \%$ of the preextinction rate of responding. In fact, for the present experiments, the measure of conditioning was the duration that a subject's head was in or near the food magazine. Extinction was deemed to have been effective when the percentage of time engaged in such magazine activity during three successive intervals of nonreinforced exposure to the CS was less than half that recorded during the final conditioning session. If the proposals by Gallistel and Gibbon (2000) are correct, both groups will reach this criterion after equivalent durations of exposure to the CS.

There was a further stage to the experiment. After the completion of the extinction trials, subjects remained in their home cages for a number of sessions before being returned to the apparatus for a series of trials that were identical to the conditioning trials, except that food was not presented. The purpose of these trials was to assess the effects of the different extinction treatments in a similar manner to that used by Shipley (1974).

\section{Method}

Subjects. The subjects were 24 experimentally naive, male, hooded Lister rats supplied by Harlan Olac (United Kingdom). They were approx- 
imately 3 months old at the start of the experiment. Prior to the experiment they were gradually reduced to $80 \%$ of their free-feeding weights and were maintained at this level throughout the experiment by being fed a restricted amount after each experimental session. The rats were housed in pairs in a light-proof room in which the lights were on for $14.5 \mathrm{hr}$ each day. With the exception of the final test session, they were tested at the same time on successive days during the period when the lights were on in their holding room.

Apparatus. Eight conditioning chambers $(24.5 \times 23.0 \times 20.0 \mathrm{~cm})$ were housed in separate light- and sound-attenuating chests. Exhaust fans in each chest provided a background masking noise of $72 \mathrm{~dB}$ (C scale). Three walls of each chamber were constructed from aluminum, one side wall was clear Perspex, and the ceiling was translucent white Perspex. A 5 -ohm speaker located on the center of the ceiling delivered a $10-\mathrm{Hz}$ click at an intensity of $83 \mathrm{~dB}(\mathrm{C}$ scale $)$. There was a $5.0 \times 6.0-\mathrm{cm}$ recessed food magazine in the front wall, into which $45-\mathrm{mg}$ food pellets (traditional formula, P. J. Noyes, Lancaster, NH) could be delivered; its base was located $0.5 \mathrm{~cm}$ above the grid floor. Subjects were required to push open a clear Perspex flap in order to gain access to the magazine. Three pairs of photo-diode sensors were set into a $1-\mathrm{cm}$ deep rectangular frame that surrounded the magazine entrance in such a manner that horizontal beams, $5 \mathrm{~mm}$ in front of the closed magazine flap, were located 10, 20, and $30 \mathrm{~mm}$ above the grid floor. Appropriate circuitry permitted the interruption of these beams to be recorded by a computer that also controlled the experimental events.

Procedure. All rats initially received a single session of magazine training. During this 40-min session, one food pellet was delivered at regular 1-min intervals. For this session only, the Perspex flap of the magazine was taped open.

In each of 10 conditioning sessions, all rats received 12 trials with the clicker presented for $10 \mathrm{~s}$. The mean intertrial interval (ITI), as measured from the start of one trial to the next, was $250 \mathrm{~s}$ (range: $180-320 \mathrm{~s}$ ). Food was not presented for 6 trials. For the remaining trials, a single food pellet was delivered at a randomly selected interval of either 5 or $10 \mathrm{~s}$ after the beginning of the CS. The sequence of reinforced and nonreinforced trials was random, with the constraint that no more than two trials of the same type could occur in succession. Following the final session of conditioning, the rats were assigned in equal numbers to the three groups in a manner that matched as closely as possible their performance in the final conditioning session.
On the following day, each group received the first of six sessions of extinction, with six trials in each session. The duration of each trial was $10 \mathrm{~s}$ for the 10-10 group, $30 \mathrm{~s}$ for the $10-30$ group, and $270 \mathrm{~s}$ for the 10-270 group. The first trial commenced $410 \mathrm{~s}$ after the start of the session, and the mean ITI was $446 \mathrm{~s}$ (range: 376-516 s). Following the sixth trial of every session, there was an interval before the end of the session of $260 \mathrm{~s}$ for the 10-10 group, $240 \mathrm{~s}$ for the 10-30 group, and $0 \mathrm{~s}$ for the 10-270 group.

On completion of the sixth session of extinction, the groups remained in their home cages for 4 days. They were then returned to the apparatus for a single session, which was conducted in the same manner as for the conditioning stage, except that food was not delivered on any trial.

The measure of conditioning was magazine activity that was deemed to have taken place whenever the infrared beams in front of a food magazine were broken. The duration of magazine activity was recorded for $5 \mathrm{~s}$ prior to each trial during both conditioning and extinction. The duration of magazine activity in the presence of the CS was recorded only on nonreinforced trials during conditioning and during successive 10-s intervals of exposure to the CS during extinction.

\section{Results}

A Type I error rate of $p<.05$ was adopted for all of the statistical tests. In the final session of conditioning, the mean durations of magazine activity in the presence of the CS on the six nonreinforced trials were $6.54 \mathrm{~s}$ for the $10-10$ group, $6.02 \mathrm{~s}$ for the 10-30 group, and $7.05 \mathrm{~s}$ for the 10-270 group. The mean durations of magazine activity in the final session of conditioning during the 5-s intervals prior to the six nonreinforced trials for the three groups, respectively, were as follows: $0.29,0.18$, and $0.14 \mathrm{~s}$. These differences during the CS and the pre-CS intervals were not significant $\left(F_{\mathrm{S}}<1\right)$.

The group mean durations of magazine activity during the first $10 \mathrm{~s}$ of each extinction trial are shown, in two-trial blocks, for the six sessions of extinction in the left-hand panel of Figure 1. Throughout the six sessions, the differences between the groups were not particularly marked, but there is an indication that extinction progressed more slowly for the 10-10 group than for the
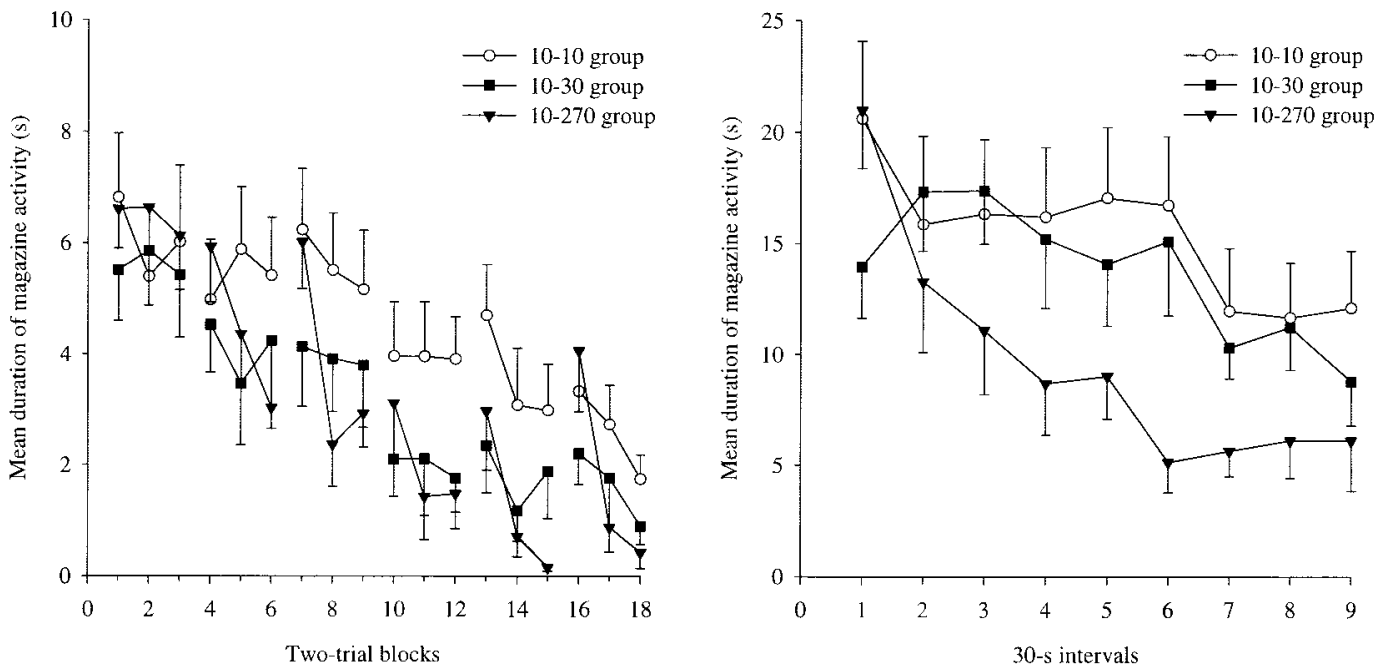

Figure 1. The mean durations of magazine activity during the first $10 \mathrm{~s}$ of each extinction trial (left panel) and during successive 30-s intervals of nonreinforced exposure to the conditioned stimulus (right panel) for the three groups of Experiment 1. Error bars show \pm 1 standard error of the mean. 
other two groups. A two-way analysis of variance (ANOVA) of individual durations of magazine activity, in two-trial blocks, revealed the effect of group was not significant, $F(2,21)=1.28$, but there was a significant effect of trial block, $F(17$, $357)=22.16$, and a significant interaction, $F(34,357)=1.72$. Tests for simple main effects (Kirk, 1968, pp. 265-270) revealed a significant difference among the groups on Trial Block $8, F(2$, $378)=3.10$. Comparisons of the group means, using the NewmanKeuls procedure, revealed a significant difference between the 10-10 group and the 10-270 group on this block. The differences between the 10-30 group and the 10-270 group, and between the $10-10$ group and the $10-30$ group, were not significant. The mean durations of magazine activity during the 5-s intervals before each of the extinction trials were $0.40 \mathrm{~s}$ for the $10-10$ group, $0.26 \mathrm{~s}$ for the 10-30 group, and $0.38 \mathrm{~s}$ for the $10-270$ group. These differences among the groups were not significant $(F<1)$.

The analysis of the results using the extinction criterion also revealed rather little difference among the groups. The mean percentage of time engaged in magazine activity during the first $10 \mathrm{~s}$ of each extinction trial was compared, for each subject, with that recorded during the six nonreinforced trials in the final session of conditioning. The mean number of trials before the percentages for three successive extinction trials were all less than half that recorded during the final session of conditioning: 24.00 for the $10-10$ group, 19.40 for the 10-30 group, and 21.10 for the $10-270$ group. These differences among the groups were not significant $(F<1)$.

The right-hand panel of Figure 1 shows the mean durations of magazine activity for successive 30-s intervals for the first $270 \mathrm{~s}$ of exposure to the CS for the three groups. The results were obtained from the first 27 extinction trials with the 10-10 group, the first 9 extinction trials with the 10-30 group, and the first complete trial for the 10-270 group. The duration of magazine activity decreased more rapidly across successive intervals for the 10-270 group than either of the other two groups, which did not differ substantially. A two-way ANOVA of individual durations of magazine activity across successive 30-s intervals revealed a significant effect of interval, $F(8,168)=12.10$, and a significant Interval $\times$ Group interaction, $F(16,168)=2.57$, but the effect of group was not significant, $F(2,21)=1.86$. Subsequent tests of simple main effects revealed a significant difference among the groups on the sixth interval, $F(2,189)=5.57$. Comparisons of the group means, using the Newman-Keuls procedure, revealed that the duration of magazine activity for this interval was significantly less for the 10-270 group than for either of the other two groups.

The results from successive intervals of exposure to the CS were also analyzed using the extinction criterion. For this analysis, the results from the first $360 \mathrm{~s}$ of nonreinforced exposure were used, which represents the entire duration that the CS was presented during extinction to the $10-10$ group. The percentage of time engaged in magazine activity during successive 30-s intervals of exposure to the CS was compared with the equivalent results from the nonreinforced trials in the final conditioning session. The mean number of intervals that were required before three intervals in succession had elapsed where the measure of responding was less than half that during conditioning were 10.13 for the $10-10$ group, 9.75 for the 10-30 group, and 6.88 for the 10-270 group. A one-way ANOVA revealed a significant difference among these means, $F(2,21)=9.28$, and subsequent comparisons using the
Newman-Keuls technique indicated that significantly fewer intervals were required to meet the criterion by the 10-270 group than either of the other two groups, which did not differ.

In the final session of the experiment, which was conducted 4 days after the completion of the extinction stage, each group received twelve 10-s nonreinforced trials with the CS. Magazine activity was relatively infrequent during these trials and was performed at a similar level by the three groups. The mean duration of magazine activity per trial was $1.83 \mathrm{~s}$ for the $10-10$ group, $1.21 \mathrm{~s}$ for the 10-30 group, and $2.24 \mathrm{~s}$ for the $10-270$ group. These differences among the groups were not significant, $F(2,21)=1.66$.

\section{Discussion}

Different groups received the same number of trials in extinction but with different durations of the CS. When the results for the first $10 \mathrm{~s}$ of each extinction trial were examined, the group that received the least amount of exposure to the CS during extinction engaged in more magazine activity than the other two groups, but this effect was not particularly pronounced. Indeed, a significant difference among the groups was recorded on only a single, two-trial block, when the duration of magazine activity was found to be significantly longer for the 10-10 group than the 10-270 group. Moreover, no differences between the groups were evident when the measure of extinction was the criterion adopted by Gallistel and Gibbon (2000). It is also interesting to note that the 10-270 group received nine times the amount of exposure to the CS during extinction than the 10-30 group, but there was no difference between the groups in terms of their behavior during the first $10 \mathrm{~s}$ of each extinction trial.

The results from the six extinction sessions provide little support for the theoretical proposals of Gallistel and Gibbon (2000). When the results from the first $10 \mathrm{~s}$ of each trial were examined, the theory predicts there should have been a difference between the groups, and yet, at least for the 10-30 group and the 10-270 group, none was observed. A further prediction of the theory is that there should have been no difference in performance between the groups when responding was examined across successive periods of exposure to the CS. Using this method of analyzing the results, however, responding by the 10-270 group was significantly weaker than for the other two groups.

The results from the final session of the experiment, in which subjects were exposed to the same conditions that they experienced during conditioning but without food being delivered, revealed no differences among the groups. The obvious explanation for this outcome is that sufficient extinction trials were given to eliminate any differences among the groups that resulted from the different extinction treatments. Tests that were similar to the one just considered were administered in each of the following experiments, but they consistently failed to reveal any differences among the groups, and they will not be considered further. From the point of view of testing the theory of Gallistel and Gibbon (2000), the results from the final test session are of little importance. The account of extinction provided by the theory is concerned with when responding will cease. The most direct method for testing predictions from the theory, therefore, is to examine responding throughout the course of extinction and not after the extinction treatment has been completed. 


\section{Experiment 2}

For the previous experiment, the onset of each extinction trial occurred at the same time within a session for the three groups, which necessarily resulted in them receiving different intervals between the end of one trial and the start of the next one. It is possible that these different intervals influenced the results when responding during the first $10 \mathrm{~s}$ of each trial was recorded. For instance, once the CS had been turned off, subjects may have remained in the vicinity of the food magazine for a short while. If the CS was presented during this period, they would have only a small distance to travel to the magazine, and this might permit a stronger CR to be recorded during the first $10 \mathrm{~s}$ of the subsequent trial than when there was a longer interval between trials. Conceivably, therefore, extinction in the first experiment was substantially more effective in the 10-270 group than in the 10-10 group, but differences in the proximity of the groups to the magazine at the start of each trial made it difficult for this outcome to be reflected in performance. Alternatively, the different extinction treatments administered to the three groups may have weakened the associative strength of the first $10 \mathrm{~s}$ of the CS to the same extent, but the CS might have been less effective at exciting a response with short rather than long intervals between the end of one trial and the start of the next. The following experiment was conducted to evaluate these different explanations for the results when responding was measured during the first $10 \mathrm{~s}$ of each trial. There were two groups in the experiment: the 10-10 group and the 10-270 group. They were treated in a similar manner to their namesakes of Experiment 1, except that during extinction the interval between the end of one trial and the start of the next trial was the same for both groups.

\section{Method}

Subjects and apparatus. The subjects were 16 male rats from the same stock and maintained in the same manner as for Experiment 1. The apparatus was the same as for Experiment 1.
Procedure. Magazine training and the 10 sessions of conditioning were conducted in the same manner as for Experiment 1. Extinction commenced the day after the completion of conditioning. Subjects were assigned in equal numbers to the two groups in such a way as to minimize differences among their performance during the final conditioning session. There were six sessions of extinction, with six nonreinforced presentations of the CS in each session. For the 10-10 group, the duration of the CS was $10 \mathrm{~s}$, and for the $10-270$ group it was $270 \mathrm{~s}$. The start of the first trial occurred after $170 \mathrm{~s}$ in each session. Thereafter the interval between the termination of one trial and the start of the next trial was variable, with a mean of 170 s (range: 100-250 s) for both groups. Procedural details that have been omitted were the same as for Experiment 1.

\section{Results}

In the final session of conditioning, the mean durations of magazine activity in the presence of the CS on the six nonreinforced trials were $5.81 \mathrm{~s}$ for the 10-10 group and $6.04 \mathrm{~s}$ for the $10-270$ group. The mean durations of magazine activity in the final session of conditioning during the 5-s intervals prior to the six nonreinforced trials for the $10-10$ and $10-270$ groups were $0.42 \mathrm{~s}$ and $0.57 \mathrm{~s}$, respectively. The differences during the $\mathrm{CS}(F<1)$ and the pre-CS, $F(1,14)=1.44$, intervals were not significant.

The left-hand panel of Figure 2 shows, in two-trial blocks, the mean durations of magazine activity that were recorded during the first $10 \mathrm{~s}$ of successive trials for the two groups. The performance of the groups was quite similar, except that for some of the earlier trials responding by the $10-10$ group was stronger than by the 10-270 group. The difference between the groups was not statistically significant. A two-way ANOVA of individual mean durations of magazine activity, for two-trial blocks, revealed a significant effect of block, $F(17,238)=6.94$, but the effect of group, $F(1,14)=1.17$, and the interaction $(F<1)$ were not significant. The mean durations of magazine activity during the 5-s intervals before each extinction trial were $0.16 \mathrm{~s}$ for the 10-10 group and $0.17 \mathrm{~s}$ for the $10-270$ group. This difference was not statistically significant $(F<1)$.
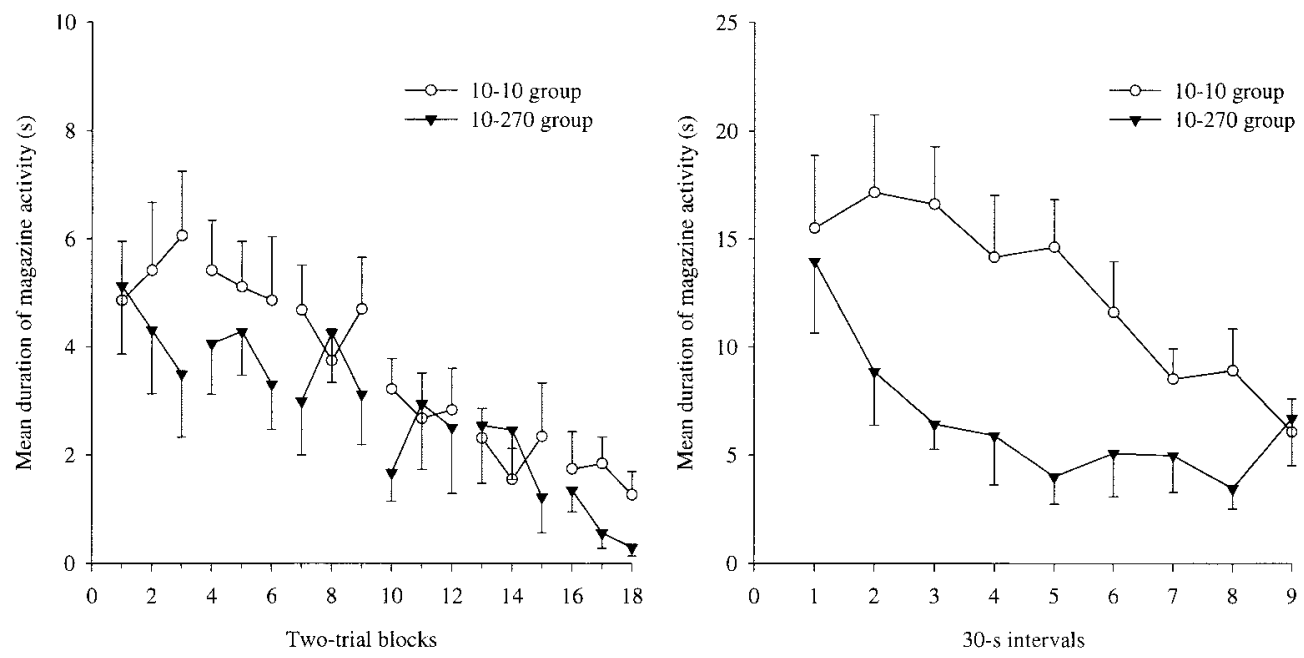

Figure 2. The mean durations of magazine activity during the first $10 \mathrm{~s}$ of each extinction trial (left panel) and during successive 30-s intervals of nonreinforced exposure to the conditioned stimulus (right panel) for the two groups of Experiment 2. Error bars show \pm 1 standard error of the mean. 
The analysis of the results in terms of the extinction criterion, based on the percentage of time engaged in magazine activity during the first $10 \mathrm{~s}$ of each trial, revealed no difference between the groups. The 10-10 group required a mean of 13.38 trials before 3 trials occurred in succession where the values of these percentages were less than half of the mean of the percentages recorded during the nonreinforced trials in the final session of conditioning. For the $10-270$ group, the mean number of trials to reach the criterion was 10.75 . This difference between the groups was not significant, $F(1,14)=1.00$.

The results from successive 30 -s intervals of exposure to the CS are shown in the right-hand panel of Figure 2. These data were obtained from the first 27 trials for the 10-10 group and the first trial for the 10-270 group. In general, the duration of magazine activity was longer for the 10-10 group than during the equivalent intervals for the 10-270 group. Support for this observation was provided by a two-way ANOVA, which revealed a significant effect of group, $F(1,14)=8.07$, of interval, $F(8,112)=5.25$, and a significant interaction, $F(8,112)=2.13$. An analysis of simple main effects revealed a significant difference between the groups for Intervals 2-6.

The results from successive intervals of exposure to the CS were analyzed further using the extinction criterion in the same manner as for Experiment 1. The 10-10 group required 10.63, 30-s intervals before the criterion was met, whereas the 10-270 group required 6.38 intervals. This difference between the groups was significant, $F(1,14)=11.80$.

\section{Discussion}

The results confirm the findings of Experiment 1 by showing again that the trial duration in extinction is relatively unimportant for determining the rate at which responding is weakened during the first $10 \mathrm{~s}$ of each trial. By way of example, it is worth noting that on Trial Block 12 in the left-hand panel of Figure 2, the 10-10 group had received $4 \mathrm{~min}$ of exposure to the CS during extinction, whereas the 10-270 group had received 108 min. Despite these differences, the duration of magazine activity for both groups was similar at this point. Admittedly, the figure shows that on certain trial blocks responding by the 10-270 group was weaker than by the 10-10 group, but these differences were not statistically reliable. Furthermore, the analysis of these results based on the extinction criterion failed to reveal a significant difference between the groups. In contrast to the previous experiment, the interval between the end of one trial and the start of the next was constant for the two groups. It is thus unlikely that the lack of a substantial difference between the results of the two groups was due to the sort of effects that were considered in the introduction to this experiment. The experiment also replicated the effect found in the previous study when the results of the two groups were compared across successive intervals of exposure to the CS in extinction. That is, responding by the $10-270$ group was generally considerably weaker than by the 10-10 group. This result was not predicted by the theory of Gallistel and Gibbon (2000), and the fact that it is reliable calls into question the account of extinction provided by the theory.

There is an inconsistency between the results from the 10-270 group in Experiment 1 and those from its namesake in Experiment 2. A look at the left-hand panel of Figure 1 shows that responding during the initial $10 \mathrm{~s}$ of the trials at the start of each test session for the 10-270 group in Experiment 1 was stronger than for the later trials. In contrast, a look at Figure 2 shows for the equivalent group of Experiment 2 that responding at the start of the CS was sometimes stronger and sometimes weaker on the initial trials than on the later trials of the test sessions. This pattern of results makes it hard to draw clear conclusions about the factors that determine the strength of responding at the beginning of long-duration trials that occur early rather than late within an extinction session. Spontaneous recovery (Pavlov, 1927) is likely to play an important role in strengthening responding during the early trials, but, on the basis of Experiment 2, it would appear this effect is by no means certain to be evident.

\section{Experiment 3}

For Experiments 1 and 2, different groups received the same number of trials during extinction, but the duration of the trials varied so that some groups received more exposure to the CS within each session than others. For instance, the 10-10 group received only $1 \mathrm{~min}$ of exposure to the CS in an extinction session, whereas the 10-270 group received $27 \mathrm{~min}$. This strategy ensured for Experiment 1 that responding during the first $10 \mathrm{~s}$ of each trial was examined at comparable points within each session. Unfortunately, this strategy also ensured that the comparison of performance across successive intervals of exposure to the CS involved results obtained in the first extinction session for the 10-270 group and the first five extinction sessions for the 10-10 group. The purpose of Experiment 3 was to determine whether this factor was responsible for the different rates of extinction that were observed using this measure. Two groups of rats first received conditioning with a 10-s CS. Both groups then received two extinction sessions in each of which the CS was presented for a total of $270 \mathrm{~s}$. For the 10-10 group there were twenty-seven 10-s trials in a session, whereas for the 10-270 group there was only a single 270-s trial. If the proposals of Gallistel and Gibbon (2000) are correct, then across successive intervals of exposure to the CS during extinction, there will be no difference between the groups in the strength of the $\mathrm{CR}$ that is recorded.

\section{Method}

Subjects. The subjects were 16 naive, male rats from the same stock and maintained in the same manner as for Experiment 1. The apparatus was the same as for Experiment 1.

Procedure. Subjects were magazine trained in the manner described for Experiment 1. They were then given 10 sessions of conditioning, the details of which were the same as for Experiment 1. Subjects were assigned in equal numbers to the two groups on the basis of their performance in the final conditioning session in such a way as to minimize differences between the groups. There were two sessions of extinction. In each session, the 10-10 group received twenty-seven 10-s presentations of the CS, and the 10-270 group received one 270-s presentation. The first trial of each session commenced after $230 \mathrm{~s}$. The mean interval between the start of successive trials was $70 \mathrm{~s}$ (range: $55-105 \mathrm{~s}$ ) for the 10-10 group. The session duration was $39 \mathrm{~min}$ for each group. Procedural details that have been omitted were the same as for Experiment 1 .

\section{Results}

Conditioning resulted in an increase in the duration of magazine activity during the CS. In the final session of conditioning, the 
mean durations of magazine activity during the nonreinforced trials were $7.70 \mathrm{~s}$ for the $10-10$ group and $7.40 \mathrm{~s}$ for the $10-270$ group. The mean durations of magazine activity during the $5 \mathrm{~s}$ prior to the three nonreinforced trials for the two groups were $0.29 \mathrm{~s}$ for the $10-10$ group and $0.24 \mathrm{~s}$ for the $10-270$ group. These differences during the CS and pre-CS intervals were not significant $(F \mathrm{~s}<1)$.

The group mean durations of magazine activity for the two groups across successive 30-s intervals of exposure to the CS, for the two extinction sessions, are shown in Figure 3. Each point on this figure represents the results obtained from three trials for the 10-10 group and from one ninth of a trial for the 10-270 group. At the start of each extinction session, performance was much the same as that recorded in the final session of conditioning. Within each session, magazine activity declined rapidly for the 10-270 group, but it was only in the second session that extinction began to be effective for the 10-10 group. A two-way ANOVA of individual mean durations of magazine activity for each 30 -s interval revealed a significant effect of group, $F(1,14)=14.08$, of interval, $F(17,238)=20.74$, and a significant interaction, $F(17$, $238)=4.25$. Subsequent tests of simple main effects revealed a significant difference between the groups on all but the first two intervals of Session 1, and for all but the first interval and the last four intervals of Session 2, Fs $(1,252)>5.45$. The mean durations of magazine activity that were recorded during the $5 \mathrm{~s}$ prior to the first trial in each session of extinction were $0.86 \mathrm{~s}$ for the $10-10$ group and $0.66 \mathrm{~s}$ for the 10-270 group. This difference between the groups was not significant $(F<1)$.

The number of 30-s intervals of exposure to the CS required by the two groups to reach the extinction criterion were consistent with the previous findings. For this analysis, individual percentages of times engaged in magazine activity during successive 30-s intervals of exposure to the CS were compared with the mean percentage obtained from the nonreinforced trials in the final session of conditioning. For the 10-10 group, a mean of 13.88 intervals was required before three trials occurred in succession

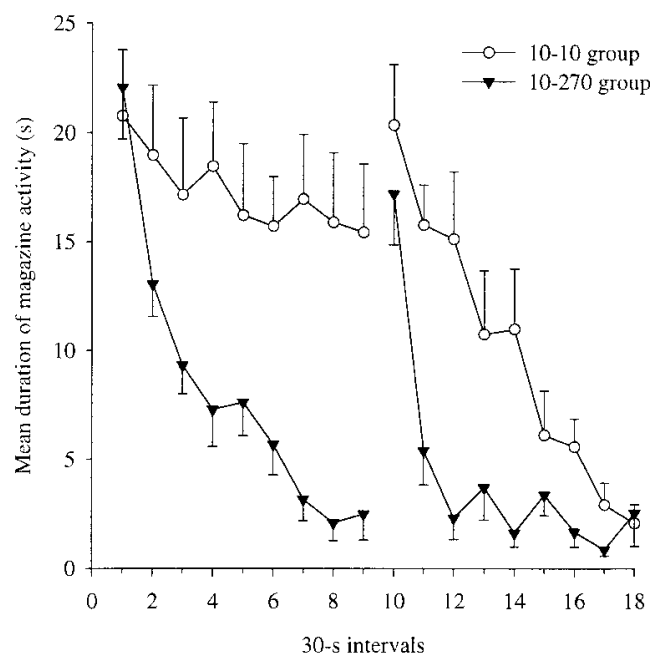

Figure 3. The mean durations of magazine activity for successive 30-s intervals of nonreinforced exposure to the conditioned stimulus for the two groups of Experiment 3. Error bars show \pm 1 standard error of the mean. where the percentages were all less than half of that recorded during conditioning. For the 10-270 group, the mean was 6.25 . This difference was statistically significant, $F(1,14)=19.63$.

\section{Discussion}

After conditioning with a 10-s CS, extinction progressed more rapidly for a group that received $270 \mathrm{~s}$ of continuous exposure to the CS in each session than for a group that received an equivalent amount of exposure but in trials that each had a duration of $10 \mathrm{~s}$. This outcome was found with two different methods for analyzing the results. The results thus demonstrate that extending the duration of the CS for extinction, from that used during conditioning, can facilitate the rate of extinction, even when the groups received the same amount of exposure to the CS in each session.

The shorter duration of magazine activity for the 10-270 group than for the 10-10 group during the extinction sessions was not predicted by the account of extinction offered by Gallistel and Gibbon (2000). Both groups received the same treatment during conditioning, and it follows that they should have performed similarly in each of the successive periods of exposure to the CS during extinction.

It is interesting to compare the present results with those reported by Shipley (1974). After conducting conditioning with a 25-s CS, he found that, provided rats received equivalent amounts of nonreinforced exposure to the CS, extinction was just as effective when the duration of each extinction trial was either $25 \mathrm{~s}$ or $100 \mathrm{~s}$. As noted in the introduction, performance during the extinction trials was not monitored. Conceivably, if he had examined the strength of responding during successive periods of nonreinforced exposure to the CS, then, in keeping with the present results, responding would have weakened more rapidly in the group that received the longer trial duration.

\section{Experiment 4}

The previous experiments have examined the effects of extending the duration of the CS on extinction. The purpose of the next two experiments is to examine the effects of the complementary procedure in which the duration of the CS is reduced for extinction. There were two groups in Experiment 4, both of which initially received conditioning with a 60 -s CS. This duration was selected to provide sufficient scope to assess the effects of conducting extinction with a shorter CS than that used for conditioning. The duration of the CS for the extinction stage was $10 \mathrm{~s}$ for the 60-10 group and $60 \mathrm{~s}$ for the 60-60 group, and both groups received $180 \mathrm{~s}$ of exposure to the $\mathrm{CS}$ in each of two sessions.

The increase in duration of the CS to $60 \mathrm{~s}$ for conditioning required a change from the previous studies in the manner in which food was presented. Thus far, on reinforced trials, food occurred once randomly either $5 \mathrm{~s}$ or $10 \mathrm{~s}$ after the start of the CS. A pilot study revealed that a single presentation of food at randomly selected intervals within a 60-s stimulus results in such weak responding that an extinction test is unlikely to be sufficiently sensitive to detect between-groups differences. Accordingly, for the final two experiments, food was delivered at regular 10-s intervals throughout the duration of the CS. As a result of this treatment, it was expected that the CS would elicit a relatively strong CR throughout its duration at the start of extinction. 
Despite the change in the manner of conditioning from the previous experiments, the theory of Gallistel and Gibbon (2000) can still be used to derive predictions concerning the effects of extinction. We noted in the introduction that one important variable for determining when extinction occurs is the rate at which the US is delivered in the presence of the CS during acquisition. As far as applying the theory is concerned, therefore, it would not seem to matter whether the US is presented more than once during each presentation of the CS or whether it is presented regularly or irregularly. Instead, the critical determinant of extinction will be the amount of exposure to the CS during extinction, relative to the rate at which the US occurs during the CS in acquisition. In other words, according to this theory there will be no difference between the groups during extinction in the next experiment, provided performance is compared across successive intervals of nonreinforced exposure to the CS.

\section{Method}

Subjects and apparatus. The 16 subjects were from the same stock and maintained in the same manner as for Experiment 1. The apparatus was the same as for Experiment 1.

Procedure. Magazine training was conducted in the same manner as for the previous experiments. Each of the 13 sessions of conditioning contained three trials with a 60-s CS. For every trial, a single food pellet was presented once every $10 \mathrm{~s}$. The first pellet was delivered $10 \mathrm{~s}$ after the start of the trial, and the last one was delivered immediately after the termination of the CS. The first trial of a session commenced after a mean of $3 \mathrm{~min}$ (range: $2-4 \mathrm{~min}$ ). Thereafter the mean interval between the start of successive trials was 19 min (range: 17-21 min). On the completion of conditioning, subjects were assigned in equal numbers to the two groups in a manner that minimized differences in the group mean durations of magazine activity that were recorded during the first $10 \mathrm{~s}$ of the three trials in the final conditioning session.

There were two sessions of extinction. The 60-60 group received three 60 -s trials in a session in an identical manner to that used for conditioning, except that food was not presented. The 60-10 group received eighteen 10-s trials in a session, with a mean interval of $190 \mathrm{~s}$ between the start of successive trials (range: $130-250 \mathrm{~s}$ ). Within a session, the start of Trials 1 , 7, and 14 for the 60-10 group coincided with the start of Trials 1, 2, and 3 for the 60-60 group.

\section{Results and Discussion}

To examine the performance of the two groups during the final session of conditioning, responding during the first $10 \mathrm{~s}$ of each of the three trials was recorded for both groups. Food was delivered after this interval, thus making it impossible to derive an accurate measure of conditioned responding during later parts of each trial. The mean duration of magazine activity for the 60-10 group was $3.49 \mathrm{~s}$ and $3.24 \mathrm{~s}$ for the $60-60$ group. The mean durations of this activity for the 5-s intervals preceding these trials was $0.56 \mathrm{~s}$ and $0.18 \mathrm{~s}$ for the two groups, respectively. The differences for the $\mathrm{CS}$ and pre-CS intervals were not significant, $F_{\mathrm{S}}(1,14)<2.66$.

The left-hand panel of Figure 4 shows the mean durations of magazine activity for the two groups during successive 30-s intervals of exposure to the CS. Each point represents the total duration of magazine activity for blocks of three successive trials for the 60-10 group and for either the first half or the second half of a trial for the 60-60 group. The durations of magazine activity were longer during the majority of the 30-s intervals for the 60-60 group than for the 60-10 group. A two-way ANOVA of individual mean durations of magazine activity across the twelve 30-s intervals of exposure to the CS during extinction revealed the effect of group was not significant, $F(1,14)=4.40$, but the effect of interval and the interaction were significant, $F_{\mathrm{s}}(11,154)>2.41$. Analysis of simple main effects revealed a significant difference between the groups for all but the second 30-s interval in the first extinction session, and for only the third interval in the second session, $F \mathrm{~s}(1,168)>4.26$. The mean durations of magazine activity for the 5-s intervals preceding the extinction trials were $0.19 \mathrm{~s}$ for the $60-10$ group and $0.24 \mathrm{~s}$ for the $60-60$ group. This difference was not significant $(F<1)$.
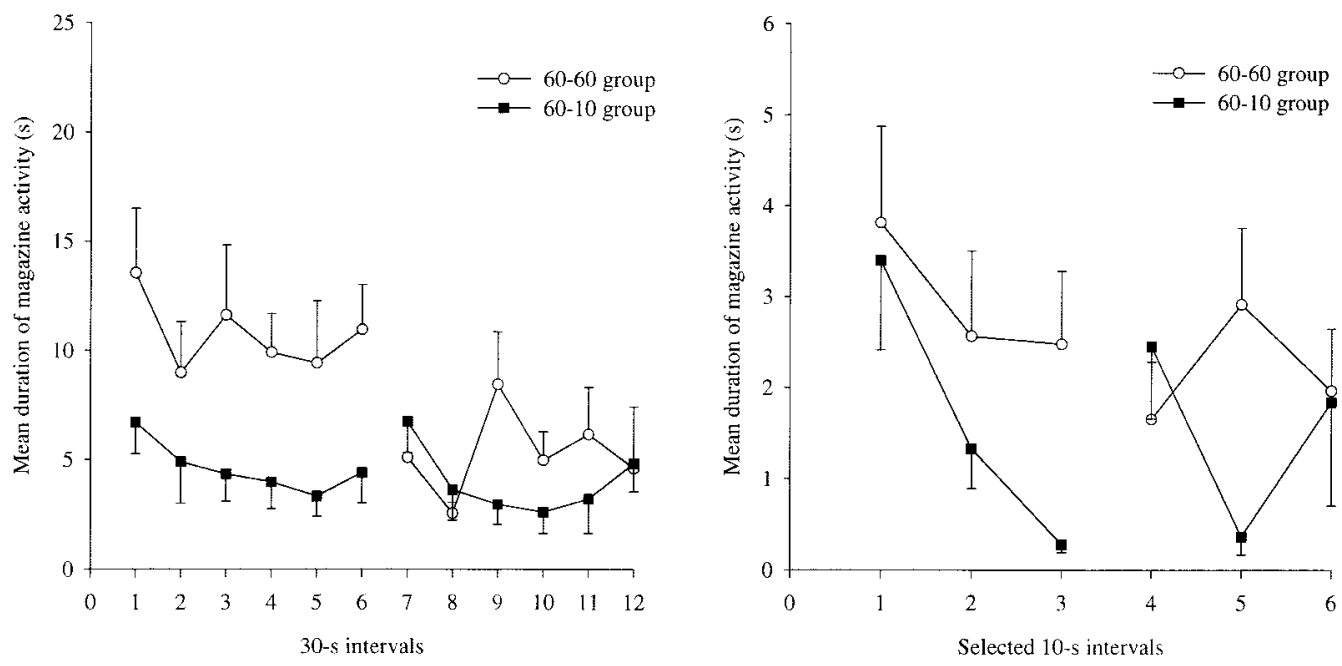

Figure 4. The mean durations of magazine activity in the two groups of Experiment 4 for successive 30-s intervals of nonreinforced exposure to the conditioned stimulus (left panel) and during the first $10 \mathrm{~s}$ of each extinction trial for the 60-60 group and of Trials 1, 7, 13, 19, 25, and 31 for the 60-10 group (right panel). Error bars show \pm 1 standard error of the mean. 
The extinction criterion used in the previous experiments was also applied to the results from the two groups. For this analysis, magazine activity in the final session of conditioning was recorded during the first $10 \mathrm{~s}$ of each trial. The number of 30 -s intervals that elapsed during extinction before the criterion was reached was 11.00 for the $60-60$ group and only 7.50 for the $60-10$ group. This difference between the groups was statistically significant, $F(1,14)=5.28$.

One explanation for the results shown in the left-hand panel of Figure 4 is that responding is particularly weak during the first $10 \mathrm{~s}$ of a trial with the CS. This might occur because, for some reason, the original training resulted in the first part of the CS acquiring less associative strength than the later portions. Alternatively, and certainly quite plausibly, during the first $10 \mathrm{~s}$ of the CS, subjects are likely to take some time to reach the magazine once the CS has been turned on, whereas they can be expected to be in the vicinity of the magazine for subsequent 10-s intervals within a trial. Each extinction trial for the 60-10 group would then involve the portion of the CS that elicited a relatively weak response, whereas presenting the CS for 60 s to the 60-60 group would involve portions of the CS that originally elicited a relatively strong response, and, on average, the latter group would show more magazine activity during extinction than the former.

To evaluate the foregoing explanation for the present results, we conducted a further analysis. The results from only the first $10 \mathrm{~s}$ of a trial were analyzed for each group. For the 60-10 group, this analysis was based on the results from Trials 1, 7, 13, 19, 25, and 31 , whereas for the 60-60 group it was based on the results from the first $10 \mathrm{~s}$ of each extinction trial. Thus, the strength of conditioned responding was compared, between groups, at equivalent points within a trial, at equivalent points within a session, and, perhaps most important, after equivalent amounts of nonreinforced exposure to the CS. The group durations of magazine activity for these selected intervals are shown in the right-hand panel of Figure 4, from which it can be seen that extinction was again more effective for the 60-10 group than for the 60-60 group. A two-way ANOVA of individual durations of magazine activity drawn from the aforementioned intervals revealed that the effect of group was not significant, $F(1,14)=1.40$, but the effect of interval, $F(5,70)=3.56$, and the interaction, $F(5,70)=2.38$, were significant. An analysis of simple main effects revealed the difference between the groups was significant on Intervals 3 and 5 , $F_{\mathrm{s}}(1,84)>3.95$.

The results demonstrate that after conditioning with a CS of a certain duration, reducing its duration for extinction results in weaker responding than if the duration of the CS remains constant. In keeping with the findings from the previous experiments, this conclusion contradicts predictions that can be derived from the account of extinction proposed by Gallistel and Gibbon (2000).

Some further comment is needed concerning the results in the left-hand panel of Figure 4, which suggest that there was a difference between the groups from the outset of extinction. It is important to note that the first point on the graph depicts the results for the first three extinction trials for the 60-10 group. The results from the first $10 \mathrm{~s}$ of exposure to the CS in extinction are shown by the left-most points in the right-hand panel of Figure 4, which reveals little difference between the groups. Moreover, there was no difference between the groups in the final session of conditioning. For these reasons, therefore, it is reasonable to infer that the associative properties of the CS were the same at the outset of extinction for both groups. The implication of the results shown in the left-hand panel, therefore, is that the effects of extinction were particularly profound after the first trial for the 60-10 group.

The results from the experiment are of value because of their implications for two theoretically uninteresting explanations for the results from the first three experiments. When extinction trials are conducted with a CS of extended duration, it is possible that the weak responding that was observed during the later part of each trial was a consequence of response fatigue, or to put it more formally, reactive inhibition (Hull, 1943). Alternatively, continued exposure to the CS might have reduced its salience and weakened its capacity to excite a response. Whatever the merits of these explanations (and we shall return to the second of them in the General Discussion), they are clearly not appropriate for the results of the 60-10 group. For this group, the duration of the CS was reduced for extinction so that each of the effects just considered would be expected to weaken responding more in the 60-60 group than in the 60-10 group, whereas the opposite outcome was found. The results from the 60-10 group are thus of particular importance because, in contrast to the other findings, they are at odds with predictions from the theory of Gallistel and Gibbon (2000) even if it is allowed that responding during extinction can be weakened by either of the processes just considered.

\section{Experiment 5}

In the previous experiment, the interval between the end of each extinction trial and the start of the next one was considerably shorter for the $10-10$ group ( $3 \mathrm{~min}$ ) than for the $60-10$ group (18 $\mathrm{min})$. There is evidence to suggest that extinction is more effective when the interval between trials is short, rather than long (Mackintosh, 1974, pp. 419-422), and it is possible that this difference between the treatment of the two groups, rather than the different duration of the CS during extinction, was responsible for the results that were found. The purpose of the present experiment was to investigate this possibility.

Four groups received conditioning with a 60 -s CS, in the same manner as for the previous experiment, followed by extinction trials. For one pair of groups the interval between the end of one extinction trial and the start of the next one was $3 \mathrm{~min}$, and the duration of the CS was either $60 \mathrm{~s}$ or $10 \mathrm{~s}$ (the 60-60-short group and the 60-10-short group, respectively). The interval between successive trials was increased to $18 \mathrm{~min}$ for the other pair of groups, which also received extinction with either a 60 -s or a $10-\mathrm{s}$ CS (the 60-60-long group and the 60-10-long group, respectively). If extinction should be facilitated by a reduction in the duration of the CS, then for each pair of groups responding will be weaker for the group that receives the 10-s CS. Furthermore, because both groups within a pair receive the same interval between trials, it would not be possible to appeal to this factor to explain any differences between their results.

\section{Method}

Subjects and apparatus. The 32 rats were from the same stock and maintained in the same manner as for Experiment 1. The apparatus was the same as for Experiment 1.

Procedure. Magazine training and conditioning with the 60-s CS was the same as in the previous experiment. Prior to extinction, rats were 
assigned in equal numbers to the four groups in the same manner as for the previous experiment. There were two sessions of extinction. For the 60-60-short group and the 60-60-long group, the duration of the CS in extinction was $60 \mathrm{~s}$, and the mean interval between the end of one trial and the start of the next was 3 min (range: 2-4 min) for the former group and $18 \mathrm{~min}$ (range: $16-20 \mathrm{~min}$ ) for the latter group. For the remaining two groups, the duration of the CS was $10 \mathrm{~s}$, and the mean interval between trials was 3 min for the $60-10$-short group and 18 min for the $60-10$-long group. Other procedural details were the same as for Experiment 4, with the consequence that all groups received a total duration of exposure to the $\mathrm{CS}$ in each extinction session of $3 \mathrm{~min}$.

\section{Results and Discussion}

In the final session of conditioning, the mean durations of magazine activity measured during the first $10 \mathrm{~s}$ of the three trials were $5.59 \mathrm{~s}, 5.39 \mathrm{~s}, 5.30 \mathrm{~s}$, and $5.70 \mathrm{~s}$ for the 60-60-short, 60-10-short, 60-60-long, and 60-10-long groups, respectively. The mean durations of magazine activity during the 10-s intervals preceding these trials were $0.15 \mathrm{~s}, 0.30 \mathrm{~s}, 0.49 \mathrm{~s}$, and $0.34 \mathrm{~s}$ for these groups, respectively. The differences during the CS and pre-CS intervals were not significant $\left(F_{\mathrm{S}}<1\right)$.

Figure 5 shows the mean durations of magazine activity during successive 30-s intervals of exposure to the nonreinforced CS for the two groups receiving short (left-hand panel) and long (righthand panel) intervals between extinction trials. Each point represents the results from three trials for the groups receiving the 10-s CS and half a trial for those receiving the 60-s CS. In both panels of the figure, it is apparent that extinction was more effective when the CS duration was $10 \mathrm{~s}$ than $60 \mathrm{~s}$. Furthermore, when the results from the two panels are compared, at least for the first extinction session, it is also apparent that responding was weaker when the interval between the extinction trials was short rather than long. This finding is consistent with other experiments, which have shown that extinction is more effective with short rather than long ITIs (e.g., Pavlov, 1927; Rescorla \& Durlach, 1987). A three-way ANOVA of individual mean durations of magazine activity during successive 30 -s periods of exposure to the CS revealed a significant effect of CS duration, $F(1,28)=29.49$, of interval between trials, $F(1,28)=5.53$, and of intervals of exposure to the CS, $F(11,308)=16.8$. The interaction between the last two of these factors was significant, $F(11,308)=3.87$, but the remaining two-way interactions were not significant $(F \mathrm{~s}<1)$. The three-way interaction was significant, $F(11$, $308)=1.90$.

Examination of the three-way interaction with a simple main effects analysis revealed that the duration of magazine activity by the groups that received a 10-s stimulus was significantly shorter for a number of 30-s intervals of extinction than by their counterparts receiving the 60-s stimulus. Thus the results for the 60-60short group and the 60-10-short group differed significantly during 30-s Intervals $1,2,3,8$, and $9, F_{\mathrm{s}}(1,336)>3.96$, and the results for the 60-60-long group and the 60-10-long group differed significantly during 30 -s Intervals $3,6,7$, and $11, F_{\mathrm{s}}(1$, 336) $>6.31$

The results of a further simple main effects analysis revealed that extinction progressed more rapidly when the interval between the end of one trial and the start of the next one was short rather than long. On 30-s Intervals 5, 6, and 8, the mean duration of magazine activity was significantly longer for the 60-60-long group than for the 60-60-short group, $F \mathrm{~s}(1,336)>4.22$, and on 30 -s Interval 5 a similar difference was found between the 60 10 -long group and the 60-10-short group, $F(1,336)=4.09$.

The mean durations of magazine activity for the 10-s intervals preceding the extinction trials were $0.21 \mathrm{~s}, 0.15 \mathrm{~s}, 0.36 \mathrm{~s}$, and $0.18 \mathrm{~s}$ for the 60-short, 10-short, 60-long, and 10-long groups, respectively. The differences among these groups were not significant $(F<1)$.

The extinction criterion analysis used in the previous experiments was again applied to the results from the present experiment. That is, the mean percentage of time engaged in magazine activity during successive 30-s periods of exposure to the CS during
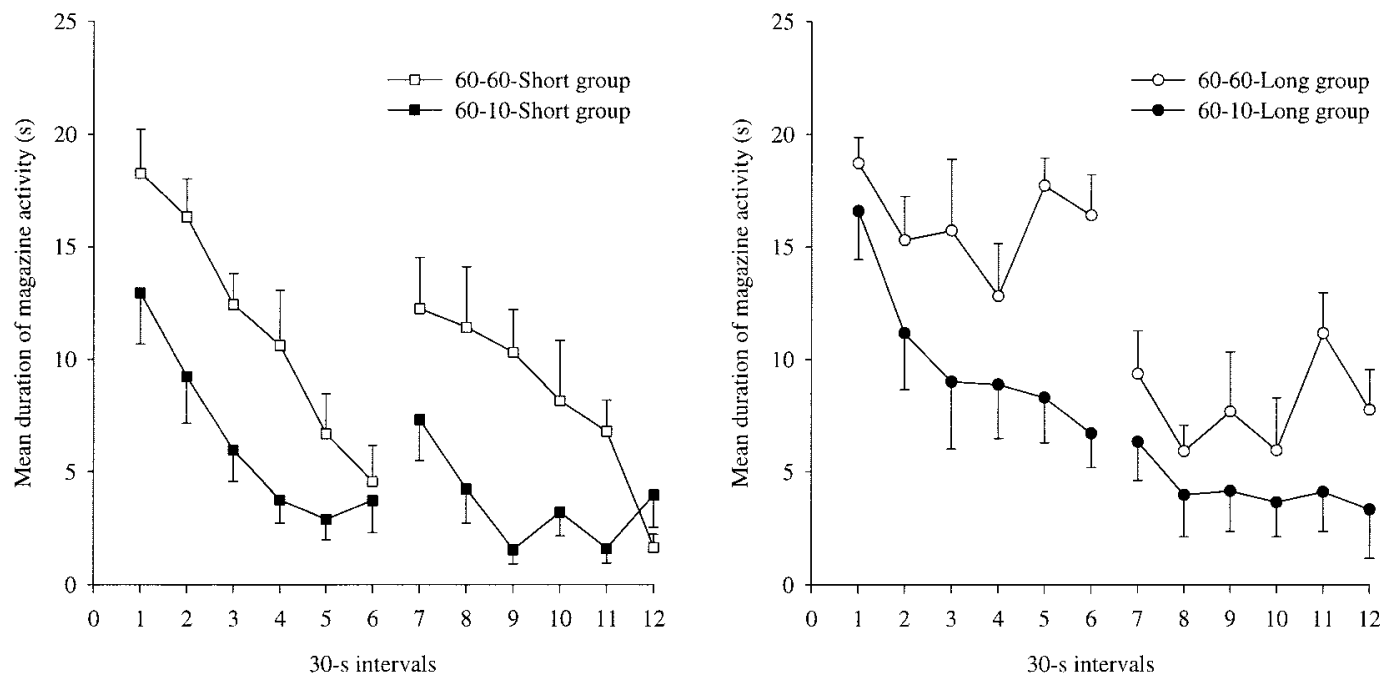

Figure 5. The mean durations of magazine activity in Experiment 5 for successive 30-s intervals of nonreinforced exposure to the conditioned stimulus for groups that received a short interval (left panel) or a long interval (right panel) between the extinction trials. Error bars show \pm 1 standard error of the mean. 
extinction was compared, for individuals, with the mean percentage recorded during the first $10 \mathrm{~s}$ of each trial during the final conditioning session. The number of 30 -s periods that elapsed before the criterion was reached was 9.25 for the 60-60-short group, 4.88 for the 60-10-short group, 10.30 for the $60-60-$ long group, and 8.38 for the $60-10-$ long group. The implication of these results is that the extinction criterion was reached more rapidly when the duration of the CS was short rather than long, and when the interval between the end of one extinction trial and the start of the next one was short rather than long. In support of these conclusions, a two-way ANOVA revealed a significant effect of CS duration, $F(1,28)=14.58$, and of interval between trials, $F(1$, $28)=7.67$, but the interaction was not significant, $F(1$, 28) $=2.02$.

The mean durations of magazine activity for the four groups during the first $10 \mathrm{~s}$ of each of the six extinction trials with the 60-s stimulus and for Extinction Trials 1, 7, 13, 19, 25, and 31 with the 10-s stimulus are shown in Figure 6. The selected results permit a comparison of the effects of extinction at the start of trials with both stimuli and after equivalent amounts of exposure to them. The pattern of results is consistent with those shown in Figure 5 by revealing that, with the exception of the first 10-s interval in each of the two sessions, the duration of magazine activity was shorter when extinction was conducted with a 10 -s rather than a 60-s stimulus. Furthermore, this effect was evident with either a short or a long interval between extinction trials. These observations were supported by the results of a three-way ANOVA of individual durations of magazine activity for the six selected intervals, which revealed a significant interaction between CS duration and interval, $F(5,140)=4.45$. Subsequent tests of simple main effects confirmed that extinction was more effective with the short- than the long-duration CS by revealing a significant effect of CS duration at Interval $5, F(1,168)=7.61$. The remaining findings from the ANOVA were as follows. There was a significant effect of the six selected intervals, $F(5,140)=13.03$, but the effects of the interval between trials $(F<1)$ and of CS duration, $F(1$, $28)=1.62$, were not significant. The two-way interactions between the first two of these factors, $F(5,140)=1.62$, and the last two $(F<1)$, as well as the three-way interaction $(F<1)$ were not significant.

The results confirm the findings from the previous experiment by demonstrating again that a reduction in the duration of the CS from that used for conditioning can result in weaker responding during extinction than when the CS duration remains constant. In the previous experiment, the interval between the end of one trial and the start of the next one was greater for the long-duration than for the short-duration $\mathrm{CS}$, which makes it difficult to know whether the length of the CS or the length of the interval between trials was responsible for our findings. Fortunately, the results from the present experiment are less ambiguous in this respect, because for each pair of groups, the interval between the end of one extinction trial and the start of the next one was constant. The experiment thus demonstrates that a reduction in the duration of the CS can facilitate extinction.

There is also an indication that extinction was more effective when the interval between successive nonreinforced trials is short rather than long. This effect was evident when performance was compared across repeated periods of exposure to the CS with both the $10 \mathrm{~s}$ and $60 \mathrm{~s}$ stimulus. The influence of the interval between trials on extinction, which has been reported on a number of occasions (see Mackintosh, 1974, for a review), is of interest to the present discussion because it again challenges the proposals of Gallistel and Gibbon (2000) concerning extinction. According to their proposals, the interval between trials during extinction will have no effect on making the decision of when to cease responding, so that the results of the groups trained with the long interval between extinction trials should have been the same as those trained with the short interval.
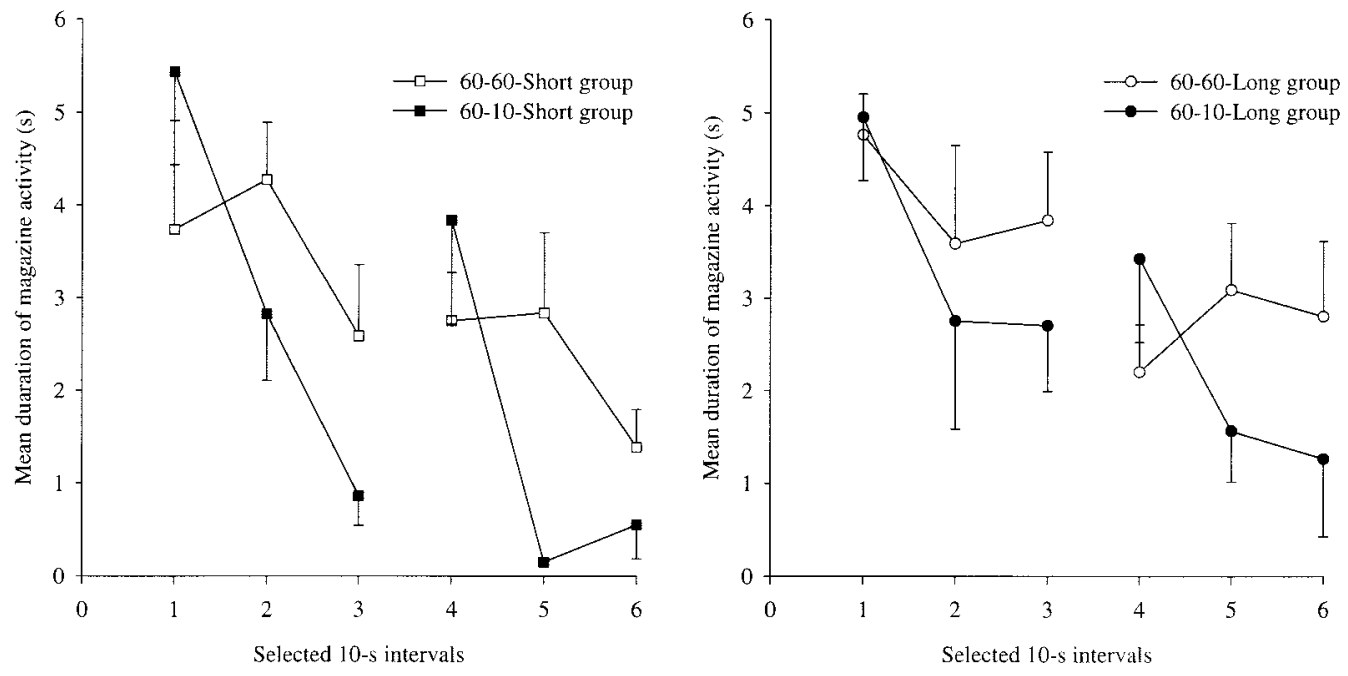

Figure 6. The mean durations of magazine activity in Experiment 5 during the first $10 \mathrm{~s}$ of each extinction trial with the 60-s conditioned stimulus (CS) or of Trials 1, 7, 13, 19, 25, and 31 with the 10-s CS for groups trained with a short (left panel) and a long (right panel) interval between trials. Error bars show \pm 1 standard error of the mean. 


\section{General Discussion}

Shipley (1974) proposed that the strength of responding during extinction is directly related to the total duration of nonreinforced exposure to the CS that subjects receive. Responding was assumed to be unrelated to the duration of each extinction trial. A similar account for the conditions of extinction follows from the theory of Gallistel and Gibbon (2000). They suggested subjects will cease responding when a ratio of two variables is greater than an extinction threshold. The numerator for this ratio is the amount of exposure to the CS since the US was last delivered, and the denominator is the amount of time in the presence of the CS during conditioning between successive presentations of the US. A clear implication of these proposals is that if two groups receive the same conditioning treatment and the same amount of exposure to the CS during extinction, then responding will be unaffected by the duration of each extinction trial. The results from each of the five experiments contradict this prediction. Both extending and reducing the duration of the CS from that used for conditioning facilitated extinction, relative to a condition in which the duration of the CS was the same for both stages. It is important to stress that this outcome was observed when the performance of the groups in extinction was compared after they had received identical durations of exposure to the CS. The strength of responding during extinction, therefore, is not just determined by the amount of nonreinforced exposure to the CS.

The effects that the amount of exposure to a CS can have on conditioned responding have been examined in rather different contexts to the present study. For instance, Albert and Ayres (1989) and Ayres, Philbin, Cassidy, Bellino, and Redlinger (1992) maintained that the total duration of exposure to a CS is a more important determinant of latent inhibition than trial duration. Clearly, this conclusion is at odds with the present results, where the performance of groups that received the same amount of exposure to the CS during extinction was greatly influenced by the trial duration. Unfortunately, it is difficult to draw any conclusions about these different effects of stimulus exposure because of the different ways in which testing for extinction and latent inhibition were conducted.

Throughout this article, it has been argued that the findings are inconsistent with the account of extinction put forward by Gallistel and Gibbon (2000). However, the theory is not just concerned with predicting when an animal will decide to stop responding; another aspect of the theory - based on scalar expectancy theory (Gibbon, 1977) - is concerned with predicting when an animal will decide to start responding. Consider Experiment 3, in which conditioning was first conducted with a 10-s CS and which might have resulted in subjects anticipating that food would be delivered $10 \mathrm{~s}$ after the start of the CS. According to scalar expectancy theory, this expectancy will result in an increase in the frequency of magazine activity during the first $10 \mathrm{~s}$ of the CS, and from then onwards this activity will decline. Thus the decline in responding that was seen in the 10-270 group throughout the first $270 \mathrm{~s}$ of exposure to the CS can be readily explained by assuming that there was a progressive decline in the expectancy of the US being delivered as the trial progressed beyond $10 \mathrm{~s}$. In support of this analysis, note that when the CS was presented for the second extinction trial in Experiment 3, responding at the start of the trial was similar to that seen during the first extinction trial. This result is just what would be expected if responding was determined by when subjects expect food to be delivered.

It is not possible for the aforementioned aspect of scalar expectancy theory to explain all of the reported results. It is unable to explain why the repeated exposure to the 10-s CS in the 10-10 group eventually resulted in a decline in responding in Experiment 3. There is also the problem of explaining the effect on extinction of reducing the CS duration. In Experiments 4 and 5, for example, subjects received conditioning trials with a 60-s CS, for which food was delivered once every $10 \mathrm{~s}$. After an equal amount of exposure to the CS in extinction, there was evidence in both studies of more magazine activity during the first $10 \mathrm{~s}$ of each trial with the 60-s than the 10-s stimulus. If the strength of the CR was determined solely by when the US was delivered during conditioning, then the performance of the two groups should have been similar on these occasions. Of course, scalar expectancy theory was not intended to provide a comprehensive account of extinction, and its failure to explain these findings merely emphasizes a need for the theory to be developed further. On the basis of the results reported previously, it would seem that the development proposed by Gallistel and Gibbon (2000) falls short of fulfilling this need.

Extinction, according to associative theories, is effective because it weakens the influence of a CS-US association that is formed during conditioning. As Gallistel and Gibbon (2000) pointed out, the problem for associative theories is to specify when nonreinforcement is effective. Consider Experiment 3 again, where groups were conditioned with a 10-s CS and then given nonreinforced trials with either a 10-s or a 270-s CS. Because the groups were matched on the amount of exposure to the CS, there were many more extinction trials with the 10-s than the 270-s stimulus. If nonreinforcement were to be effective at the end of the CS, or even 10-s after its onset, then presenting the 10-s CS for extinction should have resulted in weaker responding than the 270-s CS. But the opposite result was observed.

The results from Experiment 3 can, however, be explained if it is accepted that changes in associative strength occur throughout the CS (e.g., Ayres, Albert, \& Bombace, 1987; Moore \& Stickney, 1980; Sutton \& Barto, 1981; Wagner, 1981). To explore the implications of this type of theory for our findings, we shall focus first on the theory of Wagner (1981; Wagner \& Brandon, 2001). According to this theory, responding during continued nonreinforced exposure to a CS will decrease for two reasons. First, the associative strength of the stimulus will be reduced on a moment by moment basis so that the $\mathrm{CR}$ will become progressively weaker within each trial. The ease with which this loss of associative strength takes place, however, is deemed to diminish as the trial continues. Second, quite apart from any change in its associative strength, the protracted exposure to a stimulus is assumed to make it progressively more difficult for a response to occur as a trial progresses. It is possible for us to explain the majority of our findings by referring to both of these processes. For example, the decline in responding that was observed within each trial with the 270-s stimulus in the first three experiments may have occurred principally through the second process. Because this effect does not depend on a reduction in the associative strength of the stimulus, it follows that a strong response will be observed at the start of each trial. This effect was clearly evident with the 10-270 group for the second trial of Experiment 3. We turn now to the 
final experiments, where extinction was more effective with a $10-\mathrm{s}$ than a 60-s stimulus. This result might have occurred because repeated nonreinforced presentations of a short CS are predicted to result in a more rapid loss of associative strength than an equal amount of exposure to a long CS.

The foregoing explanations do not fit particularly comfortably with each other. For instance, the relatively slow extinction that was observed with the $10 \mathrm{~s}$ in the first three experiments implies that these trials were not particularly effective at reducing its associative strength. In contrast, we have just seen that for the results from the later experiments to be explained, it must be assumed that the 10-s CS lost its associative strength rapidly. Whether all of the present results can be explained by the theory of Wagner (1981; Wagner \& Brandon, 2001) therefore remains an open question, the resolution of which must await the outcome of detailed computer simulations. In the meantime, we can note that this associative theory offers two mechanisms that may well have been responsible for at least some of the reported findings.

There is another way in which associative theory can explain our results. If conditioning is conducted with a 10-s CS, say, which is then presented for $270 \mathrm{~s}$, responding after $10 \mathrm{~s}$ has elapsed might decline because the change from the conditions that prevailed during training results in a generalization decrement. Moreover, the extent of this decrement is likely to be more profound as more time elapses since the onset of the trial. Thus by appealing to a generalization decrement, it is possible to explain why responding became weaker as the CS was extended beyond the duration used for conditioning. For this explanation to be of value, a mechanism is needed to explain how the generalization decrement takes place. One simple suggestion is that when a CS is presented, it excites an array of different elements that become inactive, after different intervals, as the duration of the CS is increased. A CS might be represented by the elements $\mathrm{A}, \mathrm{B}, \mathrm{C}$, and $\mathrm{D}$ when it is turned on; by the elements A, B, C, after a short while; and by A alone after a long while. The changes in the associative strength of these elements could be governed by a rule such as that proposed by Rescorla and Wagner (1972). That is, elements will be eligible for excitatory conditioning if they are currently active when a US is presented, and elements will lose associative strength if they become inactive in the absence of a US. Moreover, an element must be active if it is to influence behavior.

If food were to be delivered at the end of a short CS during conditioning, then presenting a longer version of this stimulus will result in a progressive weakening of the $\mathrm{CR}$ as an increasing number of its elements become inactive. Of course, the reactivation of all of the elements at the start of the next trial will again ensure a strong response during the CS. Both of these predictions were confirmed in Experiment 3. It is also relatively simple to understand with these proposals why shortening the duration of the CS should facilitate extinction, at least when equal amounts of exposure to the nonreinforced $\mathrm{CS}$ are given. For example, in Experiment 4, where conditioning was conducted with a 60-s CS with food presented at regular intervals, a variety of different patterns excited by different portions of the CS would acquire asymptotic associative strength. During extinction, the 60-10 group might then receive repeated nonreinforced exposure with only one pattern, say ABCD, whereas the 60-60 group would receive nonreinforced exposure to a number of patterns. After one extinction trial for the 60-60 group and six extinction trials for the
10-10 group, both groups would have received the same amount of exposure to the CS but to different patterns. The six nonreinforced trials with ABCD can be expected to weaken considerably its associative strength in the 60-10 group, but the exposure to different patterns in the 60-60 group can be expected to leave the associative strength of $\mathrm{ABCD}$ relatively high. As a consequence, responding during the first $10 \mathrm{~s}$ of the second nonreinforced trial for the 60-60 group is predicted to be stronger than for the $10 \mathrm{~s}$ of the seventh extinction trial for the 60-10 group. This effect can be seen in the right-hand panel of Figure 4. The suggestion that a CS can be divided into discriminably different patterns of stimulation is by no means novel. Pavlov (1927) used this idea to explain inhibition of delay, Levis and Dubin (1973) proposed that certain aspects of performance on a signaled-avoidance task can be understood by assuming that the first part of the signal is different to later parts, and Ayres et al. (1992) explored how a similar idea might explain the effects of manipulating trial duration on latent inhibition.

There are, therefore, several ways in which the reported results can be explained in terms of associative learning theory. Where these accounts have a shortcoming, and this is true for many associative accounts of extinction, is with explaining why conditioning with a partial reinforcement schedule should result in slower extinction than with a continuous reinforcement schedule (Gibbon et al., 1980). The natural prediction from these theories is that the opposite should be found. It is possible, however, to explain the partial reinforcement extinction effect from an associative perspective. For instance, partial reinforcement might retard extinction because the generalization decrement engendered by the transition to extinction is more marked after conditioning with a continuous than with a partial reinforcement schedule (Mackintosh, 1974; Pearce et al., 1997). Alternatively, Rescorla (1999a) has suggested that partial reinforcement reduces the degree to which each nonreinforced trial can weaken the CS-US association. Of course, the theory of Gallistel and Gibbon (2000) provides a straightforward explanation for the partial reinforcement extinction effect, but, as shown in the present article, the theory gains scant support from the effects that are found when the duration of the CS is altered for extinction.

\section{References}

Albert, M., \& Ayres, J. J. B. (1989). With number of preexposures constant, latent inhibition increases with preexposure CS duration or total CS exposure. Learning and Motivation, 20, 278-294.

Ayres, J. J. B., Albert, M., \& Bombace, J. C. (1987). Extending conditioned stimuli before versus after unconditioned stimuli: Implications for real-time models of conditioning. Journal of Experimental Psychology: Animal Behavior Processes, 13, 168-181.

Ayres, J. J. B., Philbin, D., Cassidy, S., Bellino, L., \& Redlinger, E. (1992). Some parameters of latent inhibition. Learning and Motivation, 23, 269-287.

Berman, J. S., \& Katzev, R. D. (1972). Factors involved in the rapid elimination of avoidance behavior. Behavior Research and Therapy, 10, 247-256.

Gallistel, R. C., \& Gibbon, J. (2000). Time, rate, and conditioning. Psychological Review, 107, 289-344.

Gibbon, J. (1977). Scalar expectancy theory and Weber's law in animal timing. Psychological Review, 84, 279-325.

Gibbon, J., Farrell, L., Locurto, C. M., Duncan, H. J., \& Terrace, H. S. 
(1980). Partial reinforcement in autoshaping with pigeons. Animal Learning \& Behavior, 8, 45-59.

Hull, C. L. (1943). Principles of behavior. New York: Appleton-CenturyCrofts.

Kirk, R. E. (1968). Experimental design: Procedures for the behavioral sciences. Belmont, CA: Brooks Cole.

Levis, D. J., \& Dubin, W. J. (1973). Some properties of shuttle-box avoidance responding with rats receiving serially presented conditioned stimuli. Journal of Comparative and Physiological Psychology, 82, $328-344$.

Mackintosh, N. J. (1974). The psychology of animal learning. London: Academic Press.

Moore, J. W., \& Stickney, K. J. (1980). Formation of attentionalassociative networks in real time: Role of the hippocampus and implications for conditioning. Physiological Psychology, 8, 207-217.

Pavlik, W. B., \& Carlton, P. L. (1965). A reversed partial-reinforcement effect. Journal of Experimental Psychology, 70, 417-423.

Pavlik, W. B., \& Collier, A. C. (1977). Magnitude and schedule of reinforcement in rats' resistance to extinction: Within subjects. American Journal of Psychology, 90, 195-205.

Pavlov, I. P. (1927). Conditioned reflexes (G. V. Anrep, Trans.). London: Oxford University Press.

Pearce, J. M. (1994). Similarity and discrimination: A selective review and a connectionist model. Psychological Review, 101, 587-607.

Pearce, J. M., Redhead, E. S., \& Aydin, A. (1997). Partial reinforcement in appetitive Pavlovian conditioning with rats. Quarterly Journal of Experimental Psychology, 50B, 274-294.

Polin, A. T. (1959). The effects of flooding and physical suppression as extinction techniques on an anxiety motivated avoidance locomotor response. The Journal of Psychology, 47, 235-245.

Rescorla, R. A. (1999a). Partial reinforcement reduces the associative change produced by nonreinforcement. Journal of Experimental Psychology: Animal Behavior Processes, 25, 403-414.

Rescorla, R. A. (1999b). Within-subject partial reinforcement extinction effect in autoshaping. Quarterly Journal of Experimental Psychology, $52 B, 75-87$.
Rescorla, R. A., \& Durlach, P. J. (1987). The role of context in intertrial interval effects in autoshaping. Quarterly Journal of Experimental Psychology, 39B, 35-48.

Rescorla, R. A., \& Wagner, A. R. (1972). A theory of Pavlovian conditioning: Variations in the effectiveness of reinforcement and nonreinforcement. In A. H. Black \& W. F. Prokasy (Eds.), Classical conditioning: II. Current research and theory (pp. 64-99). New York: AppletonCentury-Crofts

Schiff, R., Smith, N., \& Prochaska, J. (1972). Extinction of avoidance in rats as a function of duration and number of blocked trials. Journal of Comparative and Physiological Psychology, 81, 356-359.

Sherman, R. W. (1970). Response-contingent CS termination in the extinction of avoidance learning. Behavior Research and Therapy, 8, 227-239.

Shipley, R. H. (1974). Extinction of conditioned fear in rats as a function of several parameters of CS exposure. Journal of Comparative and Physiological Psychology, 87, 699-707.

Shipley, R. H., Mock, L. A., \& Levis, D. J. (1971). Effects of several response prevention procedures on activity avoidance, avoidance responding, and conditioned fear in rats. Journal of Comparative and Physiological Psychology, 77, 256-270

Sutton, R. S., \& Barto, A. G. (1981). Toward a modern theory of adaptive networks: Expectation and prediction. Psychological Review, 88, 135170

Wagner, A. R. (1981). SOP: A model of automatic memory processing in animal behavior. In N. E. Spear \& R. R. Miller (Eds.), Information processing in animals: Memory mechanisms (pp. 5-47). Hillsdale, NJ: Erlbaum.

Wagner, A. R., \& Brandon, S. E. (2001). A componential theory of Pavlovian conditioning. In R. R. Mowrer \& S. B. Klein (Eds.), Handbook of contemporary learning theories (pp. 301-336). Mahwah, NJ: Erlbaum.

Received June 28, 2001

Revision received December 10, 2002 Accepted December 11, 2002

\section{Wanted: Your Old Issues!}

As APA continues its efforts to digitize journal issues for the PsycARTICLES database, we are finding that older issues are increasingly unavailable in our inventory. We are turning to our long-time subscribers for assistance. If you would like to donate any back issues toward this effort (preceding 1982), please get in touch with us at journals@apa.org and specify the journal titles, volumes, and issue numbers that you would like us to take off your hands. 